\title{
Outcome of Diffuse Axonal Injury Treated Conservatively
}

\author{
R J Totla ${ }^{1}$, Ishtyaque Ansari ${ }^{2}$, Kunal Mehta ${ }^{3}$ \\ ${ }^{1,2,3}$ Surgery Department, MGM Medical College \& Hospital Aurngabad, Maharashtra, Aurangabad, India
}

\begin{abstract}
Diffuse axonal injury is a brain injury in which damage in the form of extensive lesions in white matter tracts occurs over a widespread area. DAI is one of the most common and devastating types of traumatic brain injury and major cause of unconsciousness and persistent vegetative state after head trauma. It occurs in about half of all cases of severe head trauma. This study was undertaken to investigate the correlation between the degrees of injuries based on MRI findings and the mean time intervals to recovery of consciousness, their hospital stay \& improvement of GCS. Total 50 Patients studied. After taking detailed history, all the patients were Examined \& investigated. Outcome assessed at 1, 3, and 6 \& 12 months on Basis of Improvement in GCS, Time require for Consciousness \& Hospital Stay. We divided the patients into three groups according to the grade of MRI finding according to classification proposed by Adams. Mean Hospital Stay in Grade I 15.51 \pm 4.73 days. Grade II 27.87 \pm 7.03 days. Grade III 39.36 \pm 11.23 days. Mean time requires for consciousness in Grade I 6.25 \pm 2.15 days, Grade II 22.37 \pm 6.54 days. Grade III 103.54 \pm 31.07 . Our study results suggest a correlation between the mean time interval to recovery of consciousness \& hospital stay in patients with DAI and the degrees of brain injuries seen on MRI.
\end{abstract}

Keywords: Diffuse Axonal Injury, Time Require for Consciousness, Hospital Stay, Glasgow Comma Scale, MRI

\section{Introduction}

Head injuries include both injuries to the brain and those to other parts of the head, such as the scalp and skull. Head injuries can be closed or open. Closed Head injury causes two major types of traumatic brain injury (TBI); focal brain injury and diffuse axonal injury (DAI). In focal brain injury, the orbitofrontal cortex (OFC), the ventromedial prefrontal cortex (VMPFC), and the temporal pole are most frequently damaged because of the shape of the skull base ${ }^{1)}$.

Diffuse axonal injury is one of the most common pathologies of traumatic brain injury, occurring in both mild and severe cases. It is also one of the major causes of TBI patients going into a coma following their injury ${ }^{2)}$ this pathology occurs most often in car accidents, falls, or assault. In which the most common cause is car accidents. ${ }^{3)}$ Under these conditions, strong inertial forces cause axons to lose their normal elasticity and become brittle ${ }^{4)}$ DAI occurs in $40-50 \%$ of all patients admitted with TBI ${ }^{5}$

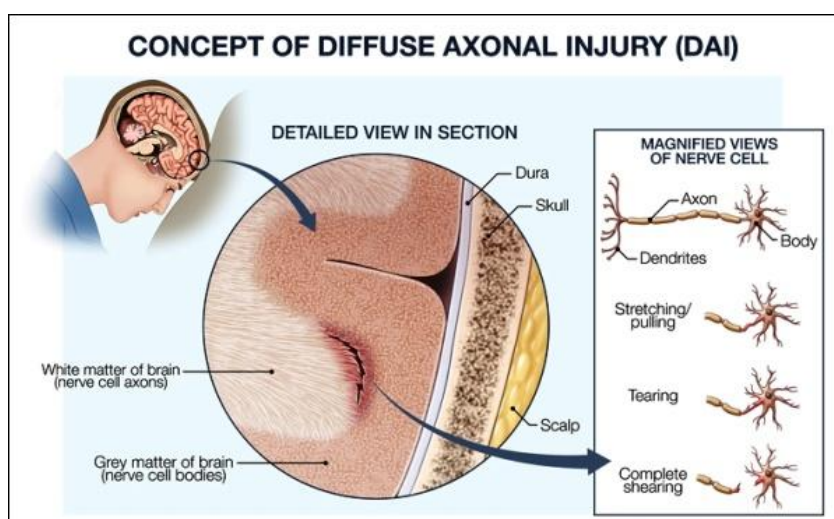

Figure: Showing Concepts of Diffuse Axonal Injury

In DAI, subcortical damage results from stretching, straining and shearing of axons as the brain moves inside the skull. The pathology of DAI is characterized histologically by Wallerian-type axonal degeneration in the parasagital white matter, corpus callosum, and dorsal upper brainstem due to shearing forces by acceleration, deceleration, or rotation of the brain ${ }^{6}$. In DAI, brain damage was originally thought to occur diffusely in the white matter ${ }^{7)}$ while the effect of such damage to the grey matter or whole brain is poorly understood. "Diffuse degeneration of the cerebral white matter" was first defined by Strich $^{8)}$ in a study of patients with severe post-traumatic dementia in 1956. The time course of the pathological changes was established by Adams et al. ${ }^{9)}$ Diffuse axonal injury can be diagnosed using clinical signs and radiological evidence. Brain magnetic resonance imaging (MRI) is known to be the most sensitive method to diagnose diffuse axonal injury, especially in gradient echo image ${ }^{10,11,12}$

Numerous studies have been performed on the outcome of and the searching for the prognostic factors of diffuse axonal injury. This study aimed to investigate the correlation between the degrees of injuries based on MRI findings and the mean time intervals to recovery of consciousness, their hospital stay \& improvement of GCS in patients with diffuse axonal injuries.

\section{Objective}

To evaluate the prognosis of patients of diffuse axonal injury treated conservatively \& to investigate the correlation between degree of injury on MRI , time require for recovery of consciousness \& hospital Stay

\section{Material and Methods}

3.1 Study Design: A Two year Retrospective \& Prospective study. The present study was conducted in the Department of Surgery, Mahatma Gandhi Mission Medical College and Hospital, Aurangabad.

3.2 Sources of Data: Patients admitted with clinical diagnosis of Diffuse Axonal Injury under the 


\section{International Journal of Science and Research (IJSR) \\ ISSN (Online): 2319-7064}

Index Copernicus Value (2013): 6.14 | Impact Factor (2014): 5.611

Department of Surgery, MGM Hospital and Medical Research Centre, Aurangabad during the study period.

3.3 Sample Size: 50 cases of Diffuse Axonal Injury

\subsection{Inclusion Criteria:}

1. All traumatic head injury managed conservatively

2. Age criteria 18 yrs to 75 years

\subsection{Exclusion Criteria:}

1. All head injury requiring surgery

2. Patient with sepsis

3. Polytrauma patient associated with chest/ abdominal/ pelvic/ long bone injury

\subsection{Method of Collection of Data}

After taking detailed history, all the patients were Examined \& investigated. Severity of DAI Assess via modified Glasgow Coma Score. According to GCS head injury is classified as: Mild with GCS 14-15, Moderate with GCS 913 , and Severe with GCS $<8$. We divided the patients into three groups according to the grade of MRI finding according to classification proposed by Adams.

Grade I: involves grey-white matter interfaces, most commonly: parasagittal regions of frontal lobes, periventricular temporal lobes, less commonly: parietal and occipital lobes, internal and external capsules, and cerebellum

Grade II: involves corpus callosum in addition to stage I locations, most commonly: posterior body and splenium but does advance anteriorly with increasing severity of injury

Grade III: involves brainstem in addition to stage I and II locations, most commonly: rostral midbrain, superior cerebellar peduncles, medial lemnisci and corticospinal tracts Assess Clinical presentations, and features of Computerized Tomography brain or MRI.Outcomes assessed at 1 month, 3 months, 6 months, One Year on Basis of Improvement In GCS, Time require Consciousness, complication \&Hospital Stay.

\subsection{Statistical Analysis}

The measures of association between the qualitative variables are assessed using chi-square test. The inference is considered statistically significant whenever $\mathrm{p} \leq 0.05$.

\section{Results}

All patients were admitted in view of Diffuse Axonal Injury.

\subsection{Mode of Injury}

Among these, the cause of hospitalization was Road traffic accident (RTA) in 47 patients, Assault in one patient, fall from first floor in one Patient \& fall of Slab in one patient.

\section{2 Distribution Patients according to Gender}

Total 50 patients were evaluated out of which 45 were male $\& 9$ were female. The Male is to female ratio wad 9:1

\subsection{Grade of D.A.I According to age of Patients}

Mean Age in Grade one Patient DAI was 35.80 \pm 16.20 . Years, Grade two DAI was 35.00 \pm 16.78 years, Grade three DAI was $35.18 \pm 15.06 y$ years.

\subsection{Complications in Patients}

Out of 31 patients of Grade One, Urinary Tract Infection seen in $2(6.45 \%)$ patients \& Bed sore in one $(3.22 \%)$ patient. Out of 8 patients of Grade Two, Urinary Tract Infection seen in two patients $(25 \%)$, Blood stream Infection seen in one patient $(12.5 \%) \&$ Bed sore in one patient $(12.5 \%)$. Out of 11 Patients of grade three DAI, Urinary Tract Infection seen in one patient $(9.09 \%)$, Ventilator Associated Pneumonia Seen in 3 Patients (27.27), Blood stream Infection seen in two patient(18.18\%) \& Bed sore in two patient $(18.18 \%)$

\subsection{Mean GCS on Admission, After 24 Hours \& at Discharge}

Mean GCS of Patients on Admission in Grade One was 9, in grade two was $8 \&$ in grade three was 7.Mean GCS of Patients after 24 hours in Grade One was 11, in grade two was $9 \&$ in grade three was 7 . Mean GCS of Patients at discharged in Grade One was 15 , in grade two was $15 \&$ in grade three was 12 .GCS of patients on admission, after 24 hours \& at discharge is statistically significant $\mathrm{p}<0.0001$

\subsection{Comparison of Mean Hospital Stay in Grading of DAI}

Grade One DAI Mean Hospital Stay is 15.51 TO 4.73 DAYS. In Grade Two DAI Mean Hospital Stay is

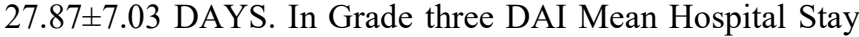
is $39.36 \pm 11.23$ DAYS. Mean Hospital Stay in grade one DAI, grade two DAI, grade three DAI is statistically Significant. $(\mathrm{f}=69.78, \mathrm{P}<0.0001)$

\begin{tabular}{|c|c|c|c|c|c|}
\hline & Grade & Mean & SD & F-value & P-value \\
\hline \multirow{3}{*}{$\begin{array}{c}\text { Hospital } \\
\text { Stay }\end{array}$} & Grade 1 & 15.51 & 4.73 & & \\
\cline { 2 - 4 } & Grade 2 & 27.87 & 7.03 & 69.78 & $\mathrm{P}<0.0001$ \\
\cline { 2 - 4 } & Grade 3 & 39.36 & 11.23 & & \\
\hline
\end{tabular}




\section{International Journal of Science and Research (IJSR)}

ISSN (Online): 2319-7064

Index Copernicus Value (2013): 6.14 | Impact Factor (2014): 5.611

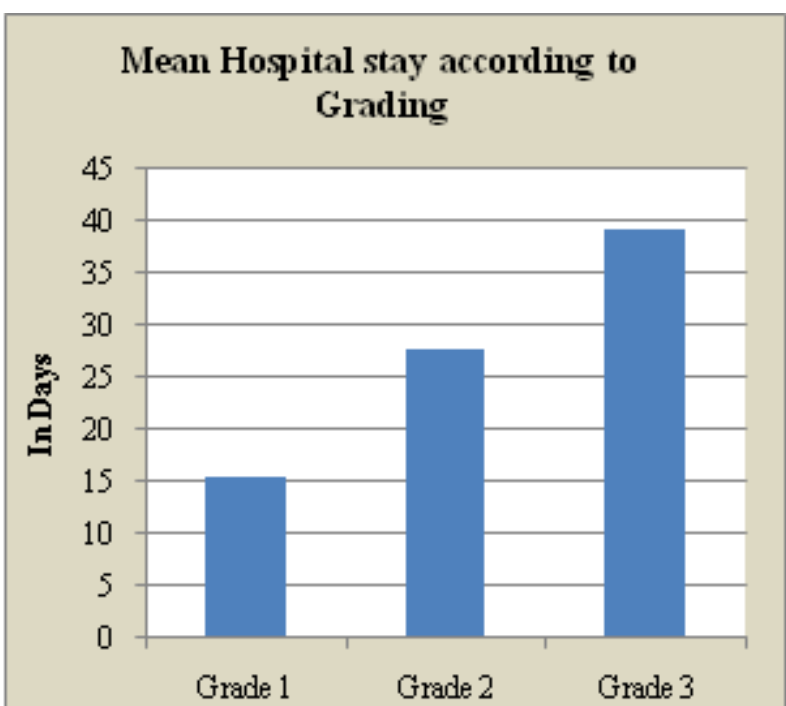

4.7 Comparison of Mean time require to consciousness in Grading of DAI

Mean time require for consciousness in grade one patients $6.25 \pm 2.15$ days. Mean time require for consciousness in grade two patients $22.37 \pm 6.54$ days. Mean time require for consciousness in grade three patients $103.54 \pm 31.07$ days. Time require for consciousness in grade one DAI, grade two DAI, grade three DAI is statistically significant. ( $\mathrm{f}=180.09$, $\mathrm{P}<0.0001)$

\begin{tabular}{|c|c|c|c|c|c|}
\hline & Grade & Mean & SD & F-value & P-value \\
\hline \multirow{2}{*}{$\begin{array}{c}\text { Time } \\
\text { Required to } \\
\text { consciousness }\end{array}$} & Grade 1 & 6.25 & 2.15 & \multirow{3}{*}{ 180.09 } & \multirow{2}{*}{$\mathrm{P}<0.0001 \mathrm{~S}$} \\
\cline { 2 - 4 } & Grade 2 & 22.37 & 6.54 & & \\
\cline { 2 - 4 } & Grade 3 & 103.54 & 31.07 & & \\
\hline
\end{tabular}

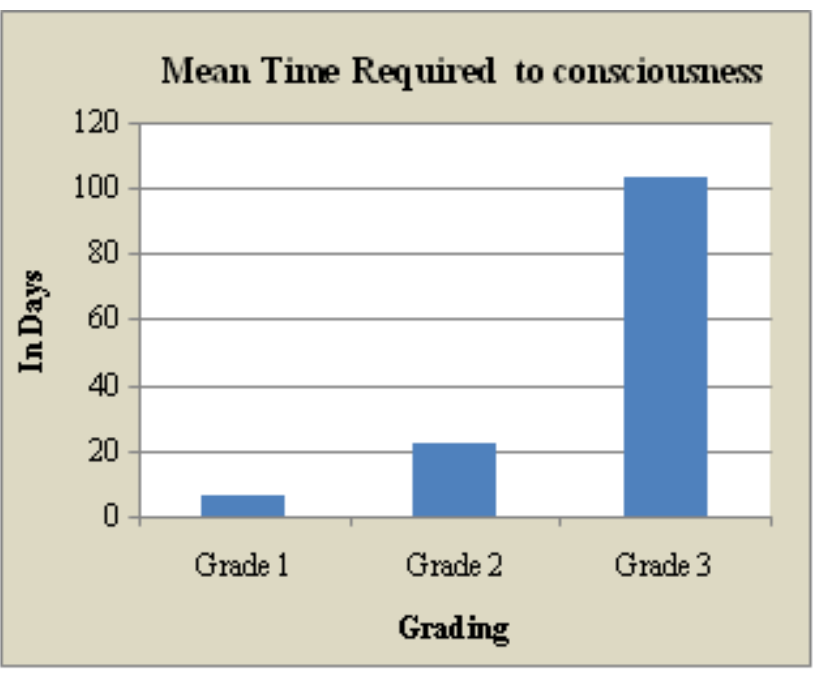

\section{Discussion}

Diffuse axonal injury (i.e., widespread damage to axons in the white matter of the brain) is well recognized as a severe post-traumatic head injury ${ }^{13)}$. It is defined as prolonged posttraumatic coma following injury without demonstrable intracranial mass lesion ${ }^{14,15.16)}$.
In 1956, $\operatorname{Strich}^{8)}$ defined the "diffuse degeneration of the cerebral white matter" in a series of patients with severe post-traumatic dementia.

Diffuse axonal injury is caused by acceleration-deceleration effects of the mechanical input to the head upon shaking of the brain within the skull ${ }^{15}, 16$. This results in shearing or stretching of nerve fibers with consequential axonal damage. Mostly, this injury mechanism is caused by traffic accidents that produce long acceleration comparatively. Determination of its severity is based on the direction, magnitude, and speed of the head motion during the injury sequence ${ }^{16)}$. Gennarelli et al. ${ }^{17)}$ Reported a high correlation b00etween the direction of the head motion in acceleration and the duration of coma. Although diffuse axonal injury could occasionally occur when the head was accelerated in a sagittal or oblique direction, it was most readily produced by coronal acceleration of the head ${ }^{17)}$. In mild injury the lesions are localized within frontotemporal cerebral white matter, stronger injury of rotatory acceleration caused additional lesions on corpus callosum and upper brain stem. Gennarelli et al. $\stackrel{17)}{ }$ reported severe injury has a tendency to cause deeper lesions.

The time course of the pathological changes has been established by Adams et al. ${ }^{20}$ In humans, instantaneous injury occurs to numerous axons in the white matter of the brain, manifested by axonal retraction balls visible on microscopic examination. Gross lesions associated with severe diffuse axonal injury in humans consist of hemorrhagic tears in the corpus callosum and in the dorsolateral quadrant of the rostral brain stem. Several days later, microglial clusters appear and the axonal retraction balls start to disappear. Months after the injury, the bulk of the white matter is reduced and long tract degeneration can be demonstrated ${ }^{17)}$.

Diffuse axonal injury can be diagnosed using clinical signs (level of consciousness and neurological deficits) and radiological findings. Zimmerman ${ }^{\frac{18}{2}}$ reported the first study of radiological diagnosis of diffuse axonal injury that includes small hemorrhagic lesions on the corpus callosum, upper brain stem, corticomedullary junction, parasagittal area, and basal ganglia. Brain computed tomographic (CT) findings lack accuracy in the prediction of a patient's outcome and do not correspond well to the patient's GCS score or neurological state ${ }^{11, \underline{19)}}$.

Brain MRI gradient echo imaging is far more sensitive than spin echo imaging on paramagnetic lesion such as hemorrhage or calcification for a long time. So, brain MRI gradient echo imaging is currently known to be the most sensitive method of confirming the presence of small hemorrhagic lesions on the white matter, corpus callosum, and brain stem in diffuse axonal injury ${ }^{10,11,12)}$.

Initial GCS in patients with head injuries strongly correlates with outcome, especially a GCS score below 5, which is associated with a poorer outcome $\mathrm{e}^{20,21,22,}$ The duration of loss of consciousness has been shown to be strongly related with the outcome in some reports ${ }^{23,24}$. The correlation between outcome and MRI findings has been studied in several reports ${ }^{10,11,12,23}$. Kim et al. ${ }^{10)}$ reported an association between higher MRI grade and longer duration of loss of 


\section{International Journal of Science and Research (IJSR) \\ ISSN (Online): 2319-7064}

Index Copernicus Value (2013): 6.14 | Impact Factor (2014): 5.611

consciousness, but not statistically significant difference between MRI grade and outcome or clinical severity. Oh et al. $\frac{12)}{2}$ reported worse outcomes in patients with brain stem lesions shown on MRI but sizes of lesions were not consistent with outcomes. Kim et al. ${ }^{11}$ reported more lesions on corpus callosum and brain stem in worse outcome in patients.

In our study In Grade One DAI Mean Hospital Stay is two to three weeks. In Grade Two DAI Mean Hospital Stay is four to five weeks. In Grade three DAI Mean Hospital Stay is seven to nine weeks

Mean time require for consciousness in grade one patients one to two weeks. Mean time require for consciousness in grade two patients three to four weeks. Mean time require for consciousness in grade three patients three to four months.

Although our relatively small number of cases was a limitation, our data were statistically significant. Therefore, in case of diffuse axonal injury except secondary hypoxic brain damage, patients with lesions on cerebral white matter and corpus callosum has a tendency to recover their consciousness earlier than patients with lesions on brain stem

\section{Conclusion}

This study shows a correlation between the time interval to recovery of consciousness in patients with diffuse axonal injury and the degrees of brain injuries seen on MRI, despite the limitation of a small study population. Patients with diffuse axonal injuries with small hemorrhagic lesions on the hemispheric white matter (lobar area) recovered consciousness within 1-2 weeks. Patients with diffuse axonal injuries with small hemorrhagic lesions on the hemispheric white matter (lobar area) \& corpus callosum recovered consciousness within 3-4 weeks In contrast; patients with diffuse axonal injuries with small hemorrhagic lesions on the hemispheric white matter (lobar area) \& corpus callosum \& the brain stem did not recover consciousness within 3-4 months. Hospital Stay Required for Grade One Diffuse axonal injury is 2 to 3 weeks. In Grade Two Diffuse Axonal Injury is 3 to 4 weeks. In Grade three Diffuse Axonal Injury is 7 to 8 weeks.

\section{References}

[1] Adams JH, Graham DI, Scott G, et al. Brain damage in fatal non-missile head injury. Journal of Clinical Pathology 1980; 33: 1132-1145.

[2] Smith, D., Meaney D., \& Shull W. Diffuse Axonal Injury in Head Trauma. J Head Trauma Rehabil. 2003; $18: 4$

[3] Adams J., Doyle D., Graham D., Lawrence A., \& McLel- lan D. Diffuse axonal injury in head injuries caused by a fall. 1984; Lancet 2:1420-1422

[4] Wang H., Ma Y. Experimental Models of Traumatic axonal injury. Journal of Clinical Neuroscience. $2010 ; 17-2$

[5] Thomas M., \& Dufour L. Challenges of diffuse axonal injury diagnosis. Rehabil Nurs.2009; 34(5):179-80.

[6] Meythaler JM, Peduzzi JD, Eleftheriou E, et al. Current concepts: Diffuse axonal injury-associated traumatic brain injury. Archives of Physical Medicine and Rehabilitation 2001; 82: 1461-1471.

[7] Gentry LR, Godersky JC, Thompson B et al. Prospective comparative study of intermediate-field MR and CT in the evaluation of closed head trauma. American journal of roentgenology :1988; 150, 673-682,

[8] Strich SJ. Diffuse degeneration of the cerebral white matter in severe dementia following head injury. J Neurol Neurosurg Psychiatry. 1956;19:163-185

[9] Adams H, Mitchell DE, Graham DI, Doyle D. Diffuse brain damage of immediate impact type. Its relationship to "primary brain stem damage" in head injury. Brain. 1977;100:489-502

[10] Kim CH, Lee HK, Koh YC, Hwang DY. Clinical analysis of diffuse axonal injury (DAI) diagnosed with magnetic resonance image (MRI) J Korean Neurosurg Soc. 1997;26:241-248.

[11] Kim HJ, Park IS, Kim JH, Kim KJ, Hwang SH, Kim ES, et al. Clinical analysis of the prognosis of the patients with cerebral diffuse axonal injuries, based on gradientecho MR imaging. J Korean Neurosurg Soc. 2001;30:168-172.

[12] Oh KS, Ha SI, Suh BS, Lee HS, Lee JS. The correlation of MRI findings to outcome in diffuse axonal injury patients. J Korean Neurosurg Soc. 2001;30(Suppl I):S20-S24.

[13] Adams JH, Graham DI, Murray LS, Scott G. Diffuse axonal injury due to nonmissile head injury in humans : an analysis of 45 cases. Ann Neurol. 1982;12:557-563

[14] Alberico AM, Ward JD, Choi SC, Marmarou A, Young HF. Outcome after severe head injury : relationship to mass lesions, diffuse injury, and ICP course in pediatric and adult patients. J Neurosurg. 1987;67:648-656.

[15] Eisenberg HM, Gary HE, Jr, Aldrich EF, Saydjari C, Turner B, Foulkes MA, et al. Initial CT findings in 753 patients with severe head injury. A report from the NIH Traumatic Coma Data Bank. J Neurosurg.1990;73:688698.

[16] Eum SW, Lim DJ, Kim BR, Cho TH, Park JY, Suh JK, et al. Prognostic factors in patients with diffuse axonal injury. J Korean Neurosurg Soc. 1998;27:1668-1674.

[17] Gennarelli T., Thibault L., Adams J., Graham D., Thompson C., \& Marcincin R. Diffuse axonal injury and traumatic coma in the primate. Ann Neurol.1982;12:564-574.

[18]Zimmerman RA, Bilaniuk LT, Genneralli T. Computed tomography of shearing injuries of the cerebral white matter. Radiology. 1978;127:393-396

[19]Zimmerman RA, Bilaniuk LT, Hackney DB, Goldberg HI, Grossman RI. Head injury : early results of comparing CT and high-field MR. AJR Am J Roentgenol. 1986;147:1215-1222

[20] Gennarelli TA, Spielman GM, Langfitt TW, Gildenberg PL, Harrington T, Jane JA, et al. Influence of the type of intracranial lesion on outcome from severe head injury. $\mathrm{J}$ Neurosurg. 1982;56:26-32.

[21]Kalff R, Kocks W, Pospiech J, Grote W. Clinical outcome after head injury in children. Childs Nerv Syst. 1989;5:156-159.

[22] Levati A, Farina ML, Vecchi G, Rossanda M, Marrubini MB. Prognosis of severe head injuries. J Neurosurg. 1982;57:779-783. 


\section{International Journal of Science and Research (IJSR) \\ ISSN (Online): 2319-7064}

Index Copernicus Value (2013): 6.14 | Impact Factor (2014): 5.611

[23] Park SW, Park K, Kim YB, Min BK, Hwang SN, Suk JS, et al. Prognostic factors in diffuse axonal injuries of brain. J Korean Neurosurg Soc. 1991; 20:983-990.

[24] Williams JM, Gomes F, Drudge OW, Kessler M. Predicting outcome from closed head injury by early assessment of trauma severity. $\mathrm{J}$ Neurosurg. 1984;61:581-585. 